\title{
Adjustment of Conditions for Combining Oxybutynin Transdermal Patch with Heparinoid Cream in Mice by Analyzing Blood Concentrations of Oxybutynin Hydrochloride
}

\author{
Yoshihito Murakami, ${ }^{a, b}$ Hidehisa Sekijima, ${ }^{c}$ Yutaka Fujisawa, ${ }^{c}$ and Kazuya Ooi ${ }^{*, b, c}$ \\ ${ }^{a}$ Sunai Pharmacy Co., Ltd.; 3-25 Kotobukicho, Kuwana, Mie 511-0061, Japan: ${ }^{b}$ Laboratory of Clinical \\ Pharmacology, Graduate School of Pharmaceutical Sciences, Suzuka University of Medical Science; 3500-3 \\ Minamitamagaki-cho, Suzuka, Mie 513-8607, Japan: and ${ }^{c}$ Department of Pharmaceutical Sciences, Suzuka \\ University of Medical Science; 3500-3 Minamitamagaki-cho, Suzuka, Mie 513-8607, Japan. \\ Received September 8, 2018; accepted December 23, 2018; advance publication released online January 25, 2019
}

The combination of skin external preparation and transdermal patch is influenced by drug absorption through the skin. We investigated the effect of heparinoid cream on the transdermal absorption of oxybutynin hydrochloride using an oxybutynin transdermal patch and determined the combined effect of these medications. Normal skin and dry dorsal skin in hairless mice were treated with heparinoid cream, followed by the application of the oxybutynin transdermal patch. A blood sample was collected from the mouse tail vein and the blood concentration of oxybutynin hydrochloride was analyzed by LC-MS/MS. Transepidermal water loss, the hydration level of the stratum corneum, and the stratum corneum thickness in the dorsal skin were measured. The blood concentration and area under the curve $(A U C)_{0 \rightarrow 24}$ of oxybutynin hydrochloride increased when the $4.0-\mathrm{cm}^{2}$ oxybutynin transdermal patch was applied $1 \mathrm{~h}$ after the application of the moisturizer, compared to the values without moisturizer. Normal skin and dry skin did not affect this result. As the hydration level of the stratum corneum and stratum corneum thickness increased before patch application by pre-treatment with moisturizer, it was suggested that transdermal absorption of oxybutynin hydrochloride was increased by skin hydration. The increased blood concentration of oxybutynin hydrochloride was regulated by changing the effective area of the patch and applying additional moisturizer at intervals. The pharmacokinetics of oxybutynin hydrochloride under the regulation of combination treatment was similar to that of treatment without moisturizer. These findings indicate that the application conditions of the oxybutynin transdermal patch and heparinoid cream influence the proper use of the patch.

Key words pharmacokinetics; oxybutynin transdermal patch; dry skin; heparinoid cream

\section{INTRODUCTION}

Overactive bladder $(\mathrm{OAB})$ is a chronic disease characterized by nocturia and frequent urination associated with urinary urgency. ${ }^{1,2)}$ In recent years, OAB has been described as an age-associated disease, since the number of OAB patients have increased with the declining birthrate and growing proportion of elderly people. ${ }^{3,4)}$ Muscarinic acetylcholine receptor antagonists such as oxybutynin hydrochloride, solifenacin succinate, and fesoterodine fumarate, are used as first-line drugs for the treatment of $\mathrm{OAB}$ as these antagonists relax the involuntary muscle of the bladder. ${ }^{5)}$ These drugs, however, induce anticholinergic side effects such as dry mouth and constipation, and patients experience a reduction in their QOL. ${ }^{6}$

The incidence of anticholinergic side effects using the oxybutynin transdermal patch, a transdermal therapeutic drug of oxybutynin hydrochloride, is lower than that of the oral form. ${ }^{7)}$ This is because the production of $N$-desethyloxybutynin (DEO), an active metabolite of oxybutynin hydrochloride, by hepatic first-pass metabolism is lower with the oxybutynin transdermal patch than with the oral form. However, daily use of the oxybutynin transdermal patch causes skin reactions such as rashes, blisters, and itching, which makes it difficult for patients to continue treatment. ${ }^{8)}$ Since skin disorders caused by the application of transdermal patches are exacerbated by a decline in the skin barrier (e.g., dry skin), treatment is required to ascertain skin conditions when the patch is used in elderly patients. ${ }^{9)}$

It has been reported that skin reactions at the application site of the transdermal patch are alleviated by applying a topical steroidal drug or moisturizer. ${ }^{10-12)}$ We previously reported in vivo studies with a dry-skin model of mice, where the Draize score of the skin after application of an oxybutynin transdermal patch was suppressed by pre-treatment with heparinoid cream. ${ }^{13)}$ Therefore, the combination therapy of oxybutynin transdermal patch and heparinoid cream may improve the adherence to drug therapy of OAB patients. The combination of skin external preparations and transdermal patches is influenced by drug absorption through the skin, which may change the pharmacokinetics of the drug released from the transdermal patch. Several studies have demonstrated that transdermal drug absorption is increased by skin hydration, after the application of moisturizers such as heparinoid cream. ${ }^{14,15)}$ It has also been reported that percutaneous absorption of a drug is altered by skin conditions such as dryness. ${ }^{16,17)}$ It is imperative that the pharmacokinetics of oxybutynin hydrochloride be considered with respect to several skin conditions to understand the proper use of oxybutynin transdermal patches in elderly OAB patients, as previous studies were limiting.

In the current study, we evaluated the effect of pretreatment with heparinoid cream on the pharmacokinetics 
of oxybutynin hydrochloride following the application of an oxybutynin transdermal patch. Skin conditions, effective area of the patch, and application interval of the moisturizer were some of the factors investigated during the study. Since the blood concentration and area under the curve $(A U C)$ of oxybutynin hydrochloride were influenced by the heparinoid cream, the co-treatment was adjusted to make the pharmacokinetics equivalent to that of oxybutynin hydrochloride alone. Normal-skin and dry-skin mouse models were used as control groups for the comparative evaluation of heparinoid cream application; the dry-skin mouse model was used to mimic the dry skin of elderly people. The application amount of the heparinoid cream and frequency of application were varied to optimize the conditions required for the combined therapy.

\section{MATERIALS AND METHODS}

Materials Oxybutynin transdermal patch $\left(\mathrm{NEOXY}^{\circledR}\right.$ TAPE $73.5 \mathrm{mg}$ ), oxybutynin hydrochloride, and oxybutynin- $d_{10}$ hydrochloride were distributed by Hisamitsu Pharmaceutical Co., Inc. (Tokyo, Japan). Heparinoid cream (Hirudoid ${ }^{\circledR}$ soft ointment) was purchased from Maruho Co., Ltd. (Osaka, Japan). Acetone was purchased from Wako Pure Chemical Industries, Ltd. (Osaka, Japan). Diethyl ether was purchased from Kanto Chemical Co., Inc. (Tokyo, Japan). Formic acid, acetonitrile, and methanol of LC-MS grade were purchased from Kanto Chemical Co., Inc. All other chemicals were reagent grade quality.

Experimental Animals Male, hairless mice (Hos: HR-1, 7 weeks) were obtained from Japan SLC Co., Inc. (Shizuoka, Japan). Experimental animals were acclimatized for 1 week at a temperature of $23 \pm 3^{\circ} \mathrm{C}$, relative humidity of $50 \pm 20 \%$, and $12 \mathrm{~h}$ light/dark cycle. The mice were allowed free access to food and water. The animal studies were approved by the Institutional Animal Care and Use Committee of Suzuka Medical Science University (approval number: No. 57).

Preparation of Dry-Skin Mice and Application of Heparinoid Cream The preparation of dry skin and the application schedule of the heparinoid cream are shown in Fig. 1. The dry-skin mice were prepared according to the method that we reported previously. ${ }^{13)}$ Absorbent cotton containing acetone-diethyl ether $(1: 1)$ mixed solution was applied to the dorsal skin of the mice for $15 \mathrm{~s}$, followed by absorbent cotton containing distilled water for $30 \mathrm{~s}$ (acetone/ether/water treatment: $\mathrm{A} / \mathrm{E} / \mathrm{W}$ treatment). The dry-skin mice were subjected to $\mathrm{A} / \mathrm{E} / \mathrm{W}$ treatment once daily for $8 \mathrm{~d}$, matched by the application period of heparinoid cream $200 \mathrm{mg}$. The $200 \mathrm{mg}$ cream was applied for $7 \mathrm{~d}$ to the normal and dry, dorsal skin. On the final day of treatment, the application interval of the heparinoid cream, before application of the oxybutynin transdermal patch, was adjusted to 1,12 , and $24 \mathrm{~h}$. Specifically, the heparinoid cream was applied twice a day for $7 \mathrm{~d}$ and $1 \mathrm{~h}$ before the application of the oxybutynin transdermal patch on the 8 th day (Figs. 1C, D). In the case of $12 \mathrm{~h}$, the heparinoid cream was applied twice a day for $7 \mathrm{~d}$, and the oxybutynin transdermal patch was applied $12 \mathrm{~h}$ after the last application (Fig. 1E). For the 24-h application, the heparinoid cream was applied twice a day for $6 \mathrm{~d}$, only once on the 7 th day, and the oxybutynin transdermal patch was applied $24 \mathrm{~h}$ after the last application (Fig. 1F).

Oxybutynin Hydrochloride Transport Study in Vivo
(A)

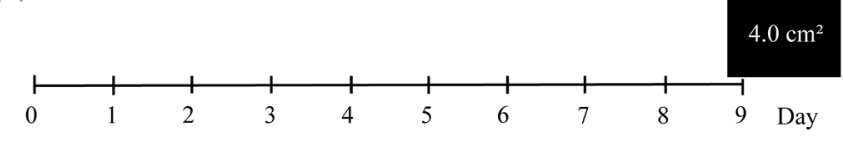

(B)

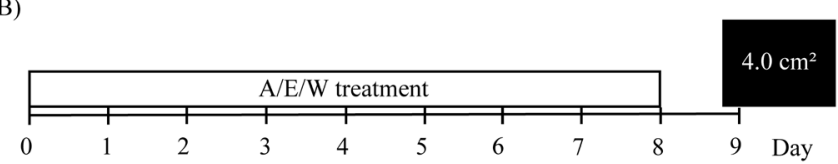

(C)

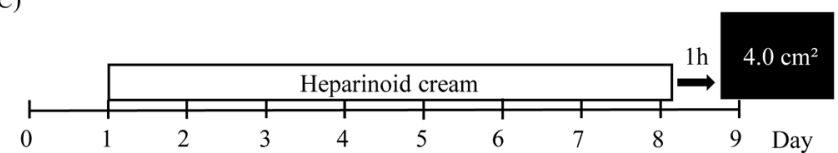

(D)
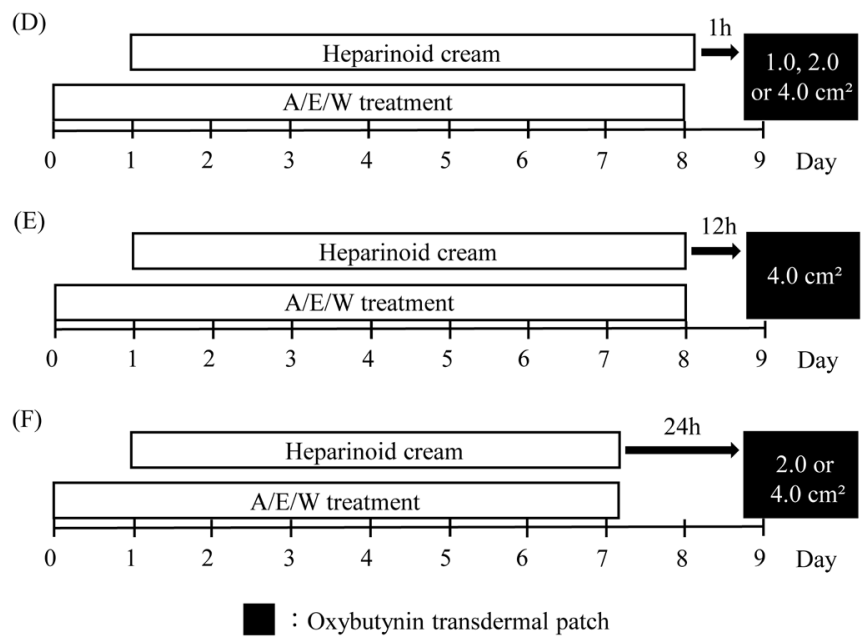

Fig. 1. Schedule for A/E/W Treatment, Application of Heparinoid Cream, and Oxybutynin Transdermal Patch

(A) Only oxybutynin transdermal patch $4.0 \mathrm{~cm}^{2}$ (oxybutynin hydrochloride: $8.4 \mathrm{mg}$ ) was applied to the dorsal skin of mice. (B) Oxybutynin transdermal patch $4.0 \mathrm{~cm}^{2}$ was applied after $\mathrm{A} / \mathrm{E} / \mathrm{W}$ treatment. (C) Oxybutynin transdermal patch $4.0 \mathrm{~cm}^{2}$ was applied after treatment with heparinoid cream. (D) Oxybutynin transdermal patches $4.0,2.0 \mathrm{~cm}^{2}$ (oxybutynin hydrochloride: $4.2 \mathrm{mg}$ ), and $1.0 \mathrm{~cm}^{2}$ (oxybutynin hydrochloride: $2.1 \mathrm{mg}$ ) were applied following $\mathrm{A} / \mathrm{E} / \mathrm{W}$ treatment and heparinoid cream treatment. (E) Oxybutynin transdermal patch $4.0 \mathrm{~cm}^{2}$ was applied $12 \mathrm{~h}$ after $\mathrm{A} / \mathrm{E} / \mathrm{W}$ treatment and application of heparinoid cream $200 \mathrm{mg}$. $(\mathrm{F})$ Oxybutynin transdermal patches 4.0 and $2.0 \mathrm{~cm}^{2}$ were applied $24 \mathrm{~h}$ after A/E/W treatment and application of heparinoid cream $200 \mathrm{mg}$.

In accordance with the experimental schedule shown in Fig. 1, an oxybutynin transdermal patch of $8.4 \mathrm{mg} / 4.0 \mathrm{~cm}^{2}$, $4.2 \mathrm{mg} / 2.0 \mathrm{~cm}^{2}$, or $2.1 \mathrm{mg} / 1.0 \mathrm{~cm}^{2}$ was applied for $24 \mathrm{~h}$ to the dorsal skin of each mouse. After applying the oxybutynin transdermal patch, blood was collected from the mouse tail vein at predetermined times. Blood samples were stored frozen at $-80^{\circ} \mathrm{C}$ until analysis. Frozen blood samples were thawed on ice and $95 \mu \mathrm{L}$ of $5.0 \mathrm{ng} / \mathrm{mL}$ oxybutynin hydrochloride- $d_{10}$ in acetonitrile-methanol $(19: 1)$ was added to $5.0 \mu \mathrm{L}$ of the sample, resulting in a final volume of $100 \mu \mathrm{L}$. The blood concentration of oxybutynin hydrochloride was analyzed by LC-MS/MS using $3 \mu \mathrm{L}$ of the supernatant after centrifugation at $4^{\circ} \mathrm{C}, 13000 \times \mathrm{rpm}$ for $3 \mathrm{~min}$.

LC-MS/MS Conditions The oxybutynin hydrochloride blood concentration measurement was performed by LC-MS/MS analysis with Prominence modular HPLC (Shimadzu Co., Ltd., Kyoto, Japan) coupled to a Triple Quad ${ }^{\mathrm{TM}}$ 5500 system (AB Sciex Co., Ltd., Tokyo, Japan). The Prominence was composed of a CBM-20A (System Controller), DGU-20A5R (Degassing Unit), LC-20AD (Solvent Delivery 
Unit), SIL-20AC (Autosampler), and CTO-20A (Column Oven). The analytical column, CAPCELL PAK C18 MG III ( $3 \mu \mathrm{m}, \phi 2.0 \times 50 \mathrm{~mm}$, SHISEIDO Co., Ltd., Kyoto, Japan), was attached to the CTO-20 A and kept at a temperature of $40^{\circ} \mathrm{C}$. The mobile phase consisted of $0.1 \%$ formic acid as solution $\mathrm{A}$ and $0.1 \%$ formic acid in acetonitrile as solution B. Uniform gradient conditions were used as follows: 10\% (3.5 min), 50\% $(0.1 \mathrm{~min}), 95 \%(0.9 \mathrm{~min})$, and $10 \%(2.9 \mathrm{~min})$ of Solution B at a flow rate of $0.3 \mathrm{~mL} / \mathrm{min}$. All sample injection volumes were $3 \mu \mathrm{L}$ and the measurement conditions of the product ions are shown in Table 1.

Measurement of Skin Barrier Function Skin barrier function was measured after $\mathrm{A} / \mathrm{E} / \mathrm{W}$ treatment pre-treatment, and $24 \mathrm{~h}$ after the application of heparinoid cream. The measurement site was located on the dorsal skin of the mouse. The stratum corneum water content, transepidermal water loss (TEWL), and skin surface $\mathrm{pH}$ were measured using a Corneometer CM 825 (Courage + Khazaka Electronic GmbH, Cologne, Germany), Tewameter TM 300 (Courage + Khazaka Electronic $\mathrm{GmbH}$ ), and Skin-pH-Meter PH 905 (Courage + Khazaka Electronic $\mathrm{GmbH})$, respectively. The humidity and temperature during the measurements were $50 \pm 10 \%$ and $25 \pm 2{ }^{\circ} \mathrm{C}$, respectively.

Hematoxylin and Eosin Staining After measuring TEWL, stratum corneum water content, and skin surface $\mathrm{pH}$, the hairless mice were euthanized by administration of an excessive amount of pentobarbital solution and the dorsal skin was excised. Resected skin samples were fixed using 4\% paraformaldehyde. The skin samples were embedded and frozen using Tissue-Tek ${ }^{\circledR}$ optimum cutting temperature compound (Sakura Finetek Japan Co., Ltd., Tokyo, Japan). Each frozen sample was sliced into $5-\mu \mathrm{m}$ sections and stained with hematoxylin and eosin according to our reported method. ${ }^{13)}$ The stained skin samples were observed under a microscope and the thickness of the stratum corneum was measured.

Statistical Analysis All data are presented as mean values \pm standard error (S.E). Statistical significance between groups was measured by the Tukey-Kramer test with differences considered significant at $p<0.05$.

\section{RESULTS}

Effect of Heparinoid Cream on Pharmacokinetics of Oxybutynin Hydrochloride Following Application of Oxybutynin Transdermal Patch To understand the effect of heparinoid cream on the systemic absorption of oxybutynin hydrochloride through the skin, the pharmacokinetics

Table 1. LC/MS/MS Parameters for the Determination

$\begin{array}{lc}\text { Precursor ions }(\mathrm{m} / \mathrm{z}) & \\ \text { Oxybutynin hydrochloride } & 358 \\ \text { Oxybutynin- } d_{10} \text { hydrochloride } & 368 \\ \text { Detection ion }(\mathrm{m} / \mathrm{z}) & \\ \text { Oxybutynin hydrochloride } & 142 \\ \text { Oxybutynin- } d_{10} \text { hydrochloride } & 152 \\ \text { Scan type } & \text { Multiple reaction monitoring } \\ \text { Polarity } & \text { Positive } \\ \text { Ion source } & \text { Turbo spray } \\ \text { Ion spray voltage }(\mathrm{V}) & 5000 \\ \text { Ion source temp. }\left({ }^{\circ} \mathrm{C}\right) & 600\end{array}$

of oxybutynin hydrochloride following the application of an oxybutynin transdermal patch $1 \mathrm{~h}$ after the final treatment with heparinoid cream was evaluated. The heparinoid cream and oxybutynin transdermal patch were applied at $200 \mathrm{mg}$ and $8.4 \mathrm{mg} / 4.0 \mathrm{~cm}^{2}$, respectively. Figure $2 \mathrm{~A}$ shows the blood concentration of oxybutynin hydrochloride applied on normal skin, dry skin, normal skin + heparinoid cream, and dry skin + heparinoid cream. There was no difference in the blood concentration of oxybutynin hydrochloride between normal and dry skin. In contrast, the blood concentration of oxybutynin hydrochloride with heparinoid cream increased drastically compared to that without heparinoid cream; whether the skin was normal or dry had no effect on this result. The $A U C$ values of normal skin + heparinoid cream and dry skin + heparinoid cream were increased approximately 1.9- and 2.3-fold compared to normal skin and dry skin values without heparinoid cream, respectively (Fig. 2B).

Skin Barrier before Application of Oxybutynin Transdermal Patch There was an increase in TEWL and decrease in hydration level of the stratum corneum in dry skin compared to that in normal skin (Figs. 3A, B). In contrast, the TEWL and hydration level of the stratum corneum with heparinoid cream were increased in both normal and dry skin (Figs. 3A, B). The stratum corneum thickness with heparinoid cream showed an increase when compared to the tissue without cream application (Figs. 4A, B). The skin surface $\mathrm{pH}$ maintained the same level in all mouse groups (Fig. 3C).

Influence of Effective Area of Oxybutynin Transdermal Patch on Pharmacokinetics of Oxybutynin Hydrochloride with Dry Skin Pretreated with Heparinoid Cream To re-
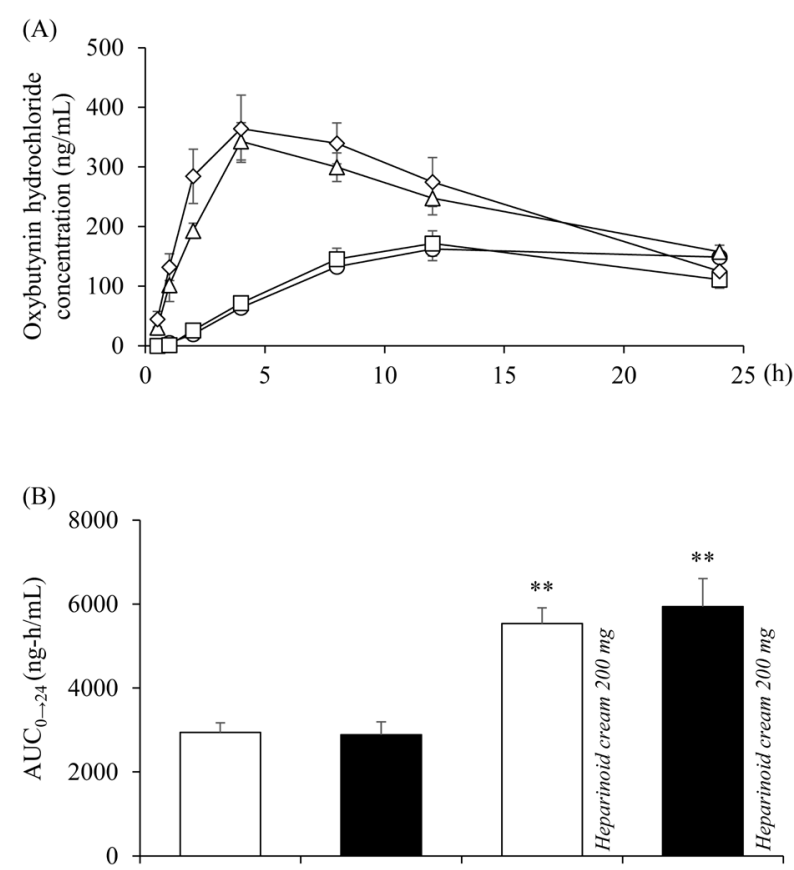

Fig. 2. (A) Time Courses of Blood Concentration of Oxybutynin Hydrochloride Following the Application of Oxybutynin Transdermal Patch $8.4 \mathrm{mg} / 4.0 \mathrm{~cm}^{2}$ and Pre-treatment of Heparinoid Cream

Circle, normal skin + oxybutynin transdermal patch; square, dry skin + oxybutynin transdermal patch; triangle, normal skin + heparinoid cream + oxybutynin transdermal patch; and rhombus, dry skin + heparinoid cream + oxybutynin transdermal patch. (B) Comparison of $A U C_{0 \rightarrow 24}$ of oxybutynin hydrochloride in normal skin (open columns) and dry skin (closed columns), with and without heparinoid cream. $* *: p<0.01 v s$. Normal skin (Tukey-Kramer test). Data are presented as means \pm S.E. $(n=4-5)$. 
A

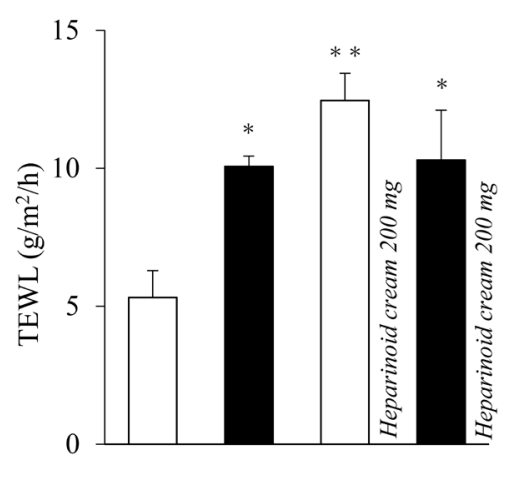

C

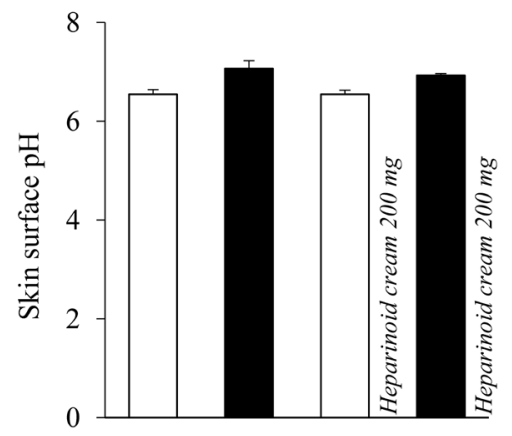

B

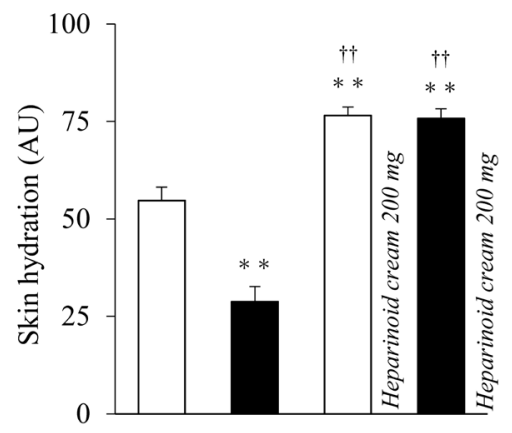

Fig. 3. Comparison of TEWL (A), Skin Hydration (B), and Skin Surface pH (C) in Normal Skin (Open Columns) and Dry Skin (Closed Columns), with and without Heparinoid Cream

$* p<0.05,{ }^{* *} p<0.01 v s$. Normal skin, ${ }^{\dagger \dagger} p<0.01 v s$. Dry skin (Tukey-Kramer test). Data are presented as means \pm S.E. $(n=4-5)$.

A

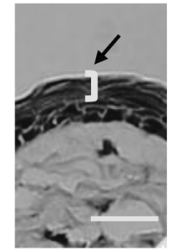

Normal skin

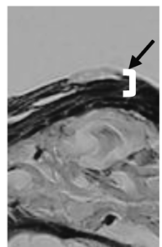

Dry skin

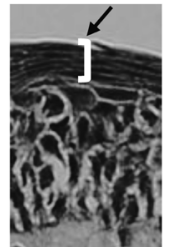

Normal skin

Heparinoid cream $200 \mathrm{mg}$

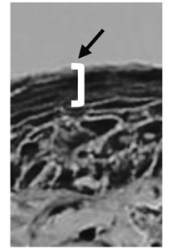

Dry skin

Heparinoid cream $200 \mathrm{mg}$
B

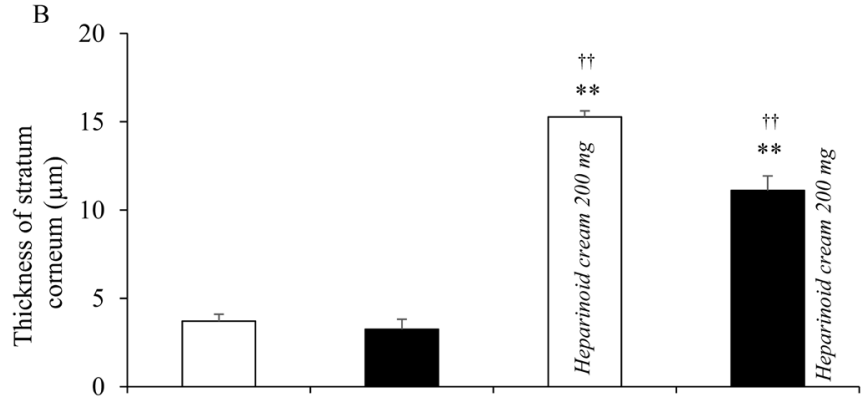

Fig. 4. Stratum Corneum Images (A) and Thickness of Stratum Corneum (B) before Application of Oxybutynin Transdermal Patch in Normal Skin (Open Columns) and Dry Skin (Closed Columns), with and without Heparinoid Cream

Scale bar in (A) represents $20 \mu \mathrm{m} .{ }^{* *} p<0.01 v s$. Normal skin, ${ }^{\dagger} p<0.01 v s$. Dry skin (Tukey-Kramer test). Data are presented as means \pm S.E. $(n=4-5)$.

duce the increased $A U C$ of oxybutynin hydrochloride, the effective area of the oxybutynin transdermal patch was reduced from $8.4 \mathrm{mg} / 4.0 \mathrm{~cm}^{2}$ to $2.1 \mathrm{mg} / 1.0 \mathrm{~cm}^{2}$. The $A U C_{0 \rightarrow 24}$ of oxybu-
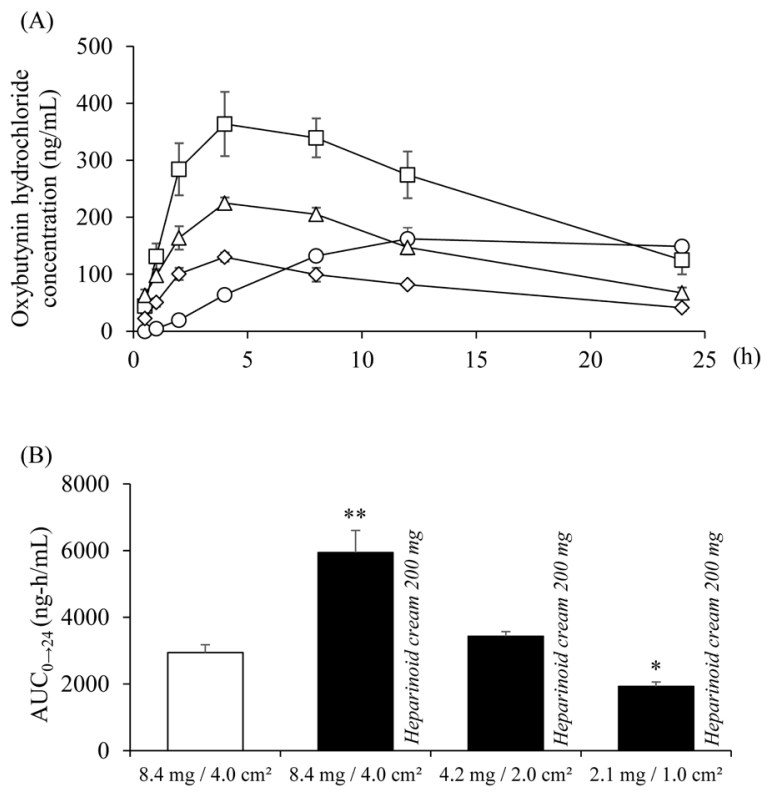

Fig. 5. (A) Effect of Administration Area of Oxybutynin Transdermal Patch on the Blood Concentration of Oxybutynin Hydrochloride

Circle, normal skin + oxybutynin transdermal patch $8.4 \mathrm{mg} / 4.0 \mathrm{~cm}^{2}$; square, dry skin + heparinoid cream + oxybutynin transdermal patch $8.4 \mathrm{mg} / 4.0 \mathrm{~cm}^{2}$; triangle, dry skin + heparinoid cream + oxybutynin transdermal patch $4.2 \mathrm{mg} / 2.0 \mathrm{~cm}^{2}$. and rhombus, dry skin + heparinoid cream + oxybutynin transdermal patch $2.1 \mathrm{mg} / 1.0 \mathrm{~cm}^{2}$. (B) Comparison of $A U C_{0 \rightarrow 24}$ of oxybutynin hydrochloride. open column, normal skin; closed columns, dry skin. $* p<0.05, * * p<0.01 v s$. normal skin (Tukey-Kramer test). Data are presented as means \pm S.E. $(n=4-5)$.

tynin hydrochloride decreased and was dependent on the reduced effective area of the oxybutynin transdermal patch. The increase in blood concentration of oxybutynin hydrochloride 
(A)

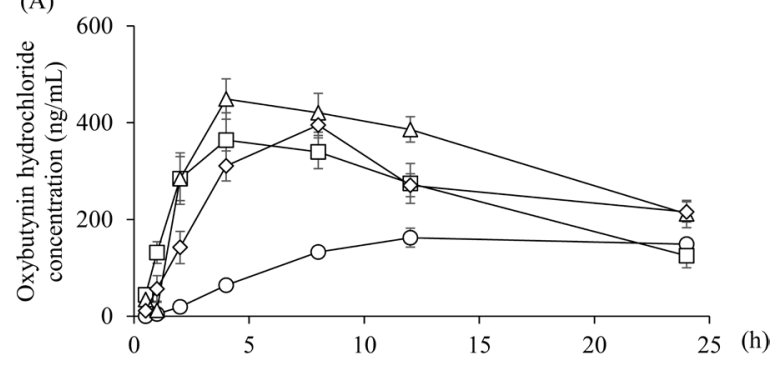

(B)

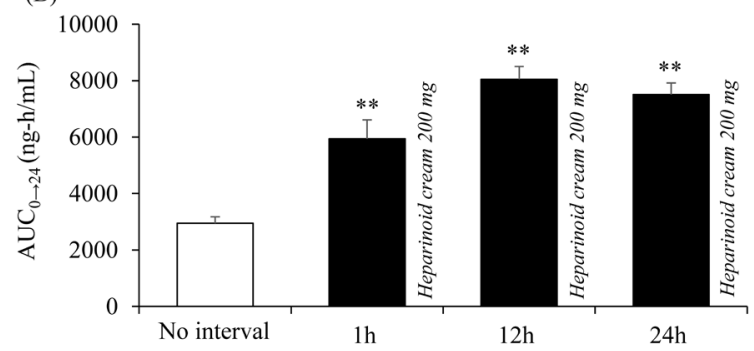

Fig. 6. (A) Influence on Blood Concentration of Oxybutynin Hydrochloride on Interval of Application of Heparinoid Cream and Oxybutynin Transdermal Patch $8.4 \mathrm{mg} / 4.0 \mathrm{~cm}^{2}$

Circle, normal skin + oxybutynin transdermal patch; square, dry skin + oxybutynin transdermal patch $1 \mathrm{~h}$ after application of heparinoid cream; triangle, dry skin + oxybutynin transdermal patch $12 \mathrm{~h}$ after application of heparinoid cream; and rhombus, dry skin + oxybutynin transdermal patch $24 \mathrm{~h}$ after application of heparinoid cream. (B) Comparison of $A U C_{0 \rightarrow 24}$ of oxybutynin hydrochloride. open column, normal skin; closed columns, dry skin. $* * p<0.01$ vs. normal skin (Tukey-Kramer test). Data are presented as means \pm S.E. $(n=4-5)$.

at $0-4 \mathrm{~h}$ was similar between all groups (Fig. 5).

Effect of Application Interval of Heparinoid Cream on Pharmacokinetics of Oxybutynin Hydrochloride with Dry Skin Figure 6(A) shows the pharmacokinetics of oxybutynin hydrochloride when the application intervals of the heparinoid cream were adjusted to 1,12 , and $24 \mathrm{~h}$ before the application of the oxybutynin transdermal patch $8.4 \mathrm{mg} / 4.0 \mathrm{~cm}^{2}$. When the application interval was $24 \mathrm{~h}$, the blood concentration of oxybutynin hydrochloride increased slowly compared to that with application intervals of 1 and $12 \mathrm{~h}$ (Fig. 6A). The $A U C_{0 \rightarrow 24}$ of oxybutynin hydrochloride did not change in all groups (Fig. 6B).

Skin Barrier $24 \mathrm{~h}$ after Application of Heparinoid Cream The TEWL $24 \mathrm{~h}$ after the application of heparinoid cream was lower than that with dry skin, and no significant difference was found between it and the normal skin value (Fig. 7A). In addition, the hydration level of the stratum corneum $24 \mathrm{~h}$ after the application of heparinoid cream was lower than that of normal skin, but it was significantly increased compared to that of dry skin (Fig. 7B). There was no significant difference in stratum corneum thickness with normal skin, dry skin, and $24 \mathrm{~h}$ after the application of heparinoid cream (Figs. $8 \mathrm{~A}, \mathrm{~B}$ ).

Pharmacokinetics of Oxybutynin Hydrochloride Following Application of Oxybutynin Transdermal Patch $4.2 \mathrm{mg} / 2.0 \mathrm{~cm}^{2} 24 \mathrm{~h}$ after Treatment with Heparinoid Cream The combination of an application interval of $24 \mathrm{~h}$ for heparinoid cream and oxybutynin transdermal patch $4.2 \mathrm{mg} / 2.0 \mathrm{~cm}^{2}$ was evaluated to achieve the blood pharmacokinetics of oxybutynin hydrochloride without heparinoid cream. The blood concentration of oxybutynin hydrochloride was similar until $8 \mathrm{~h}$, regardless of the presence of heparinoid
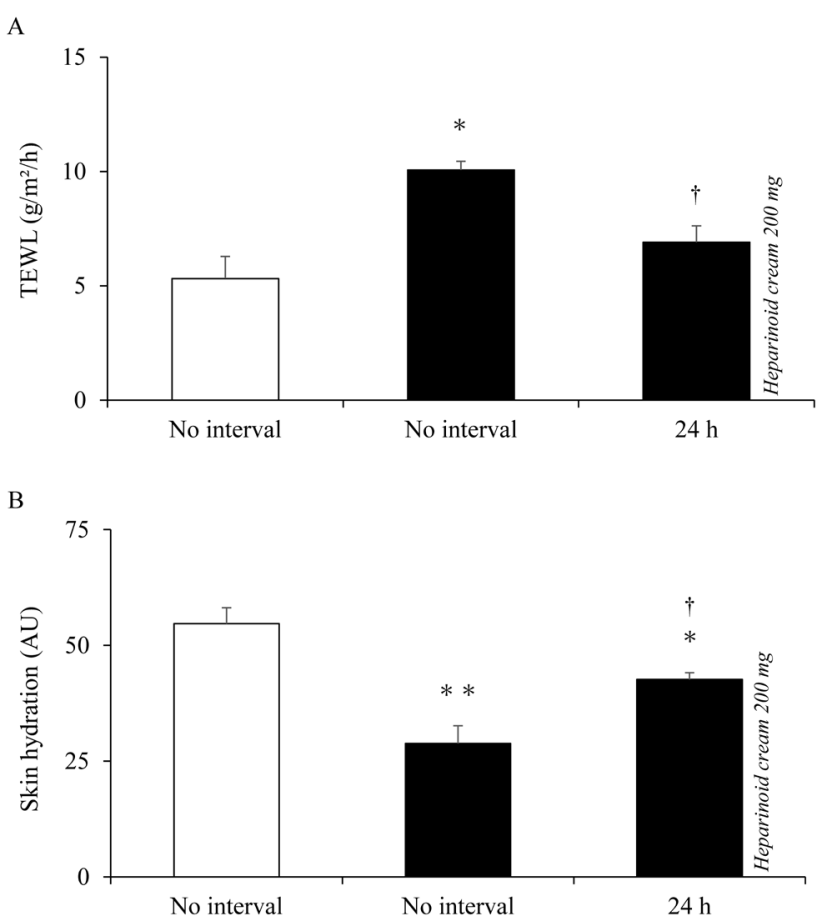

Fig. 7. Comparison of TEWL (A) and Skin Hydration (B) in Normal Skin (Open Columns) and Dry Skin (Closed Columns), without Heparinoid Cream (No Interval) or $24 \mathrm{~h}$ after Application of Heparinoid Cream $(24 \mathrm{~h})$

${ }^{*} p<0.05,{ }^{* *} p<0.01$ vs. normal skin, ${ }^{\dagger} p<0.05 v s$. dry skin (Tukey-Kramer test). Data are presented as means \pm S.E. $(n=3-5)$.

cream; a decrease was then seen from 8 to $24 \mathrm{~h}$ (Fig. 9A). However, the $A U C_{0 \rightarrow 24}$ of oxybutynin hydrochloride was the same with or without heparinoid cream treatment (Fig. 9B).

\section{DISCUSSION}

Transdermal patches are widely used in medical practice as the application method is simple. ${ }^{18-20)}$ However, as the amount of drug delivered into the body via the skin depends on the state of the skin surface, the external preparation and transdermal patch should be carefully monitored when using combined treatment. In this study, we evaluated the effective area of the oxybutynin transdermal patch and intervals of application between the patch and heparinoid cream. Based on these results, we also attempted to optimize the conditions of the combined patch and moisturizer use.

$\mathrm{A} / \mathrm{E} / \mathrm{W}$ treatment for associated dry skin is widely used in the dermatological research field. ${ }^{21-23)}$ Dry skin associated with $\mathrm{A} / \mathrm{E} / \mathrm{W}$ treatment results in an increase in TEWL and decrease in skin hydration because the interlamellar lipid is eluted. ${ }^{24)}$ Generally, the transdermal absorption of a drug increases depending on the TEWL value. ${ }^{25)}$ The dry-skin mouse model used in this study showed that the TEWL and hydration level of the stratum corneum were increased and decreased by $\mathrm{A} / \mathrm{E} / \mathrm{W}$ treatment, respectively. However, the blood concentration of oxybutynin hydrochloride with dry skin was equivalent to that with normal skin, despite the TEWL of dry skin being higher than that of normal skin (Fig. 2). Tsai et al. reported that the percutaneous absorption rate of a drug of log partition coefficient $(\log P) 3.9$ was poorly correlated with the increase in TEWL. ${ }^{25)}$ Since oxybutynin has a $\log P$ of 4.3 , the trans- 
A

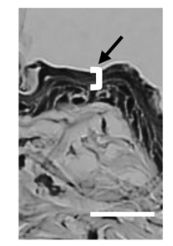

Normal skin

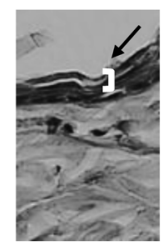

Dry skin

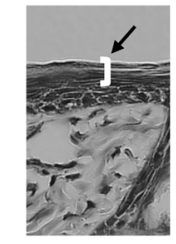

Dry skin

$24 \mathrm{~h}$ after application of heparinoid cream $200 \mathrm{mg}$
B

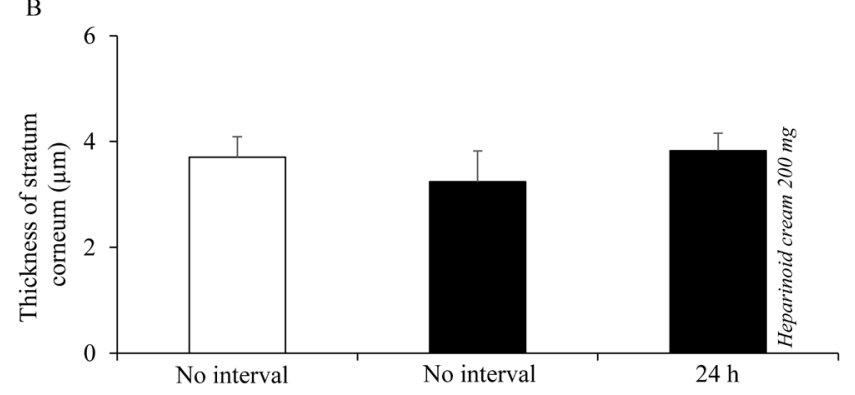

Fig. 8. Stratum Corneum Images (A) and Thickness of Stratum Corneum (B) in Normal Skin (Open Column) and Dry Skin (Closed Columns), without Heparinoid Cream (No Interval) or 24h after Application of Heparinoid Cream (24h)

White bar in part (A) represents $20 \mu \mathrm{m}$. Data are presented as means \pm S.E. $(n=3-5)$.

dermal absorption rates of oxybutynin hydrochloride between normal and dry skin were equivalent, considering that there was no difference in the blood concentration levels. Based on these findings, the dry-skin mouse model used in this study was appropriate for evaluating the effect of heparinoid cream on the transdermal absorption of oxybutynin hydrochloride.

The blood concentrations of oxybutynin hydrochloride in normal skin and dry skin were increased in a shorter time with heparinoid cream than without heparinoid cream (Fig. 2A). Similarly, the $A U C_{0 \rightarrow 24}$ of oxybutynin hydrochloride was also increased (Fig. 2B). A moisturizer hydrates the stratum corneum and changes the characteristics of the skin surface, such as the TEWL, hydration level of the stratum corneum, and skin surface $\mathrm{pH}^{26,27)}$ These factors have been shown to affect transdermal absorption of drugs. ${ }^{13,24,28)}$ In this study, the hydration level of the stratum corneum in both normal and dry skin was increased by heparinoid cream; however, the skin surface $\mathrm{pH}$ was unchanged (Fig. 3). In addition, the stratum corneum thickness of the skin treated with heparinoid cream was increased compared to that of the untreated skin (Fig. 4). Skin hydration increases the hydration level of the stratum corneum and swells it. ${ }^{29)}$ In this swollen stratum corneum, the fluidity increases due to the disorder of the lipid sequence, and the stratum corneum barrier function, which is important for drug permeability, is lowered. It has been reported that the transdermal absorption of a drug increases with deterioration of the stratum corneum barrier function. ${ }^{30)}$ For that reason, we suggest that the enhancing effect of transdermal drug absorption, caused by skin hydration from the application of heparinoid cream, contributes to an increase in blood concentration of oxybutynin. In this study, it is presumed that the skin barrier function was improved, because the TEWL $24 \mathrm{~h}$ after application of heparinoid cream decreased to a similar
(A)

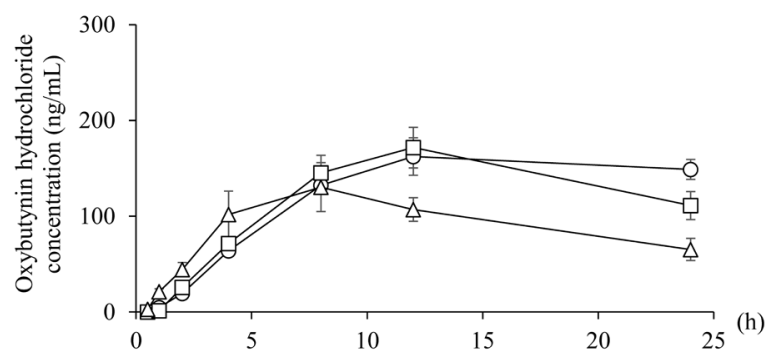

(B)

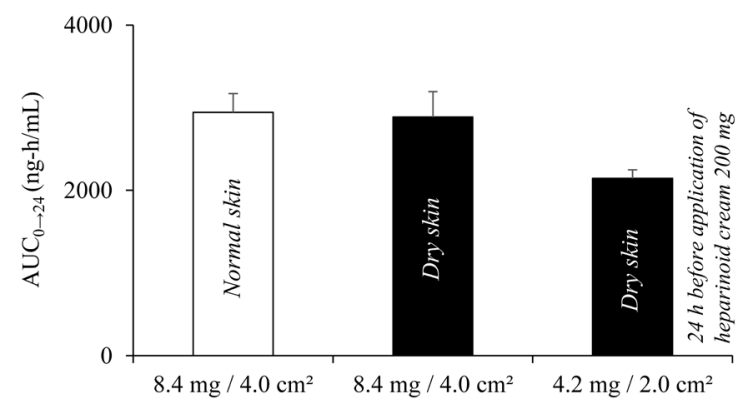

Fig. 9. (A) Combination of Oxybutynin Transdermal Patch $4.2 \mathrm{mg} / 2.0 \mathrm{~cm}^{2} 24 \mathrm{~h}$ after Application of Heparinoid Cream

Circle, normal skin + oxybutynin transdermal patch $8.4 \mathrm{mg} / 4.0 \mathrm{~cm}^{2}$; square, dry skin + oxybutynin transdermal patch $8.4 \mathrm{mg} / 4.0 \mathrm{~cm}^{2}$; triangle, dry skin + oxybutynin transdermal patch $4.2 \mathrm{mg} / 2.0 \mathrm{~cm}^{2} 24 \mathrm{~h}$ after application of heparinoid cream. (B) Comparison of $A U C_{0 \rightarrow 24}$ of oxybutynin hydrochloride. Open column, normal skin; closed columns, dry skin. Data are presented as means \pm S.E. $(n=3-5)$.

level as that of normal skin and the hydration level of the stratum corneum was higher than that of dry skin (Figs. 7A, B). Furthermore, we assumed that the condition of the skin had recovered from hydration, since no significant difference was found in the stratum corneum thickness between normal skin, dry skin, and $24 \mathrm{~h}$ after application of heparinoid cream (Figs. $8 \mathrm{~A}, \mathrm{~B})$. From these results, it was concluded that temporary hydration of the skin by heparinoid cream had promoted percutaneous absorption of oxybutynin hydrochloride. However, the increase in percutaneous absorption is not only caused by skin hydration, because the blood concentration of oxybutynin hydrochloride when the oxybutynin transdermal patch was applied $24 \mathrm{~h}$ after application of the heparinoid cream was increased compared with that of normal skin. Glycerin is widely used as a base material for external preparations and is known to increase the skin permeability of drugs by causing water retention and lipid structure changes to the stratum corneum. ${ }^{14,31)}$ Moisturizer containing concentrated glycerin such as heparinoid cream and urea ointment is possibility to increase in percutaneous absorption of the oxybutynin hydrochloride. Increased blood concentration and $A U C$ are factors involved in the development of side effects. Therefore, optimization of the conditions for combining heparinoid cream and oxybutynin transdermal patch based on this enhancing effect was required.

The pharmacokinetics after application of a transdermal patch is dependent on the effective area of the patch. Therefore, the pharmacokinetics of oxybutynin hydrochloride based on the change in the application effective area of the transdermal patch was evaluated. As a result, the $A U C_{0 \rightarrow 24}$ of oxybutynin hydrochloride after application of the heparinoid 
cream decreased and was dependent on the effective area of the patch. In addition, when the oxybutynin transdermal patch was downsized by one-half $\left(4.0 \rightarrow 2.0 \mathrm{~cm}^{2}\right)$, the $A U C_{0 \rightarrow 24}$ of oxybutynin hydrochloride was similar to that without heparinoid cream (Fig. 5B). Therefore, it is suggested that reducing the effective area of the oxybutynin transdermal patch was useful because the $A U C$ of oxybutynin hydrochloride increased by applying the heparinoid cream. The short-term increase in blood concentration of oxybutynin hydrochloride could not be improved (Fig. 5A). Lubrication of the skin by moisturizer depends on the number of times the moisturizer is used. ${ }^{32-34)}$ Therefore, we proposed to prolong the application of the heparinoid cream using intervals. This inhibited the increase in blood concentration of oxybutynin hydrochloride at $0-4 \mathrm{~h}$ following the application of the patch. The blood concentration curve of oxybutynin hydrochloride at $0-8 \mathrm{~h}$ following the application of the oxybutynin transdermal patch $24 \mathrm{~h}$ after application of the heparinoid cream increased smoothly compared to that of the 1- and 12-h applications (Fig. 6A). Namba reported that skin hydration after application of heparinoid cream sharply increases immediately following application and gradually decreases up to the value before application. ${ }^{35)}$ Since the hydration effect of glycerin decreases over time, the effect on the skin also decreases. ${ }^{36}$ )

Therefore, the state of the skin surface $24 \mathrm{~h}$ after application of heparinoid cream was recovered to that before application of the moisturizer, suggesting that such phenomena affected the increase in blood concentration of oxybutynin hydrochloride by inhibiting transdermal delivery of the drug. Based on these findings, we evaluated the pharmacokinetics of oxybutynin hydrochloride when the oxybutynin transdermal patch $2.0 \mathrm{~cm}^{2}$ was applied $24 \mathrm{~h}$ after application of the heparinoid cream. The blood concentration until $8 \mathrm{~h}$ after application of the oxybutynin transdermal patch showed the same trend as that without heparinoid cream treatment, but the blood concentration decreased after $12 \mathrm{~h}$ (Fig. 9A). Furthermore, the $A U C_{0 \rightarrow 24}$ showed the same level when compared to that without heparinoid cream (Fig. 9B), indicating that the application interval of the moisturizer was controlled and the effective area of the patch was useful for treating OAB by combination therapy.

The pharmacokinetics of combined oxybutynin hydrochloride and heparinoid cream could be made equivalent to that of oxybutynin hydrochloride alone by adjusting the method of co-treatment with the cream and transdermal patch. However, the blood concentration of oxybutynin hydrochloride using the combination of heparinoid cream and the oxybutynin transdermal patch decreased gradually with time; the values decreased compared to those of the non-combination treatment at $24 \mathrm{~h}$ (Figs. 2, 5, 6, 9).

Generally, a transdermal patch utilizing a hydrophobic matrix, such as the oxybutynin transdermal patch, can maintain a drug level in the body for an extended duration, as drug release from an adhesive portion obeys Higuchi's law. ${ }^{37,38)}$ However, the dissolution rate of the drug decreases after a certain period. This occurs because the unexposed portion of the drug shifts from the surface to the inside as times lapses, and the distance required for drug release increases. ${ }^{39,40)}$ Takano et al. reported that the blood concentration of bisoprolol decreased with time in the case of a high initial release rate of bisoprolol from a transdermal patch. ${ }^{41)}$ Therefore, the decrease in blood concentration of oxybutynin hydrochloride after $12 \mathrm{~h}$ in the heparinoid cream-treated group suggests that the oxybutynin hydrochloride in the patch was drastically released within a short time. Future studies on the releasing properties of oxybutynin hydrochloride from the oxybutynin transdermal patch after treatment with heparinoid cream are required to achieve prolonged efficacy against OAB.

\section{CONCLUSION}

In this study, we showed that the pharmacokinetics of oxybutynin hydrochloride increased by moisturizing care with heparinoid cream. In addition, the increased blood concentration of oxybutynin hydrochloride by treatment with heparinoid cream could be adjusted by changing the application time of the moisturizer and the application effective area of the oxybutynin transdermal patch. The findings in this study have provided useful information regarding the oxybutynin transdermal patch and the proper use of other transdermal patches.

Conflict of Interest The authors declare no conflict of interest.

\section{REFERENCES}

1) Gormley EA, Lightner DJ, Burgio KL, Chai TC, Clemens JQ, Culkin DJ, Das AK, Foster HE Jr, Scarpero HM, Tessier CD, Vasavada SP, American Urological Association, Society of Urodynamics, Female Pelvic Medicine \& Urogenital Reconstruction. Diagnosis and treatment of overactive bladder (non-neurogenic) in adults: AUA/SUFU guideline. J. Urol., 188 (Suppl.), 2455-2463 (2012).

2) Lee UJ, Scott VC, Rashid R, Behniwal A, Wein AJ, Maliski SL, Anger JT. Defining and managing overactive bladder: disagreement among the experts. Urology, 81, 257-262 (2013).

3) Homma Y, Yamaguchi O, Hayashi K, Neurogenic Bladder Society Committee. An epidemiological survey of overactive bladder symptoms in Japan. BJU Int., 96, 1314-1318 (2005).

4) Sexton CC, Coyne KS, Thompson C, Bavendam T, Chen CI, Markland A. Prevalence and effect on health-related quality of life of overactive bladder in older Americans: results from the epidemiology of lower urinary tract symptoms study. J. Am. Geriatr. Soc., 59, $1465-1470$ (2011)

5) Gormley EA, Lightner DJ, Faraday M, Vasavada SP, American Urological Association, Society of Urodynamics, Female Pelvic Medicine. Diagnosis and treatment of overactive bladder (nonneurogenic) in adults: AUA/SUFU guideline amendment. J. Urol., 193, 1572-1580 (2015)

6) Benyamini Y, Goner-Shilo D, Lazarov A. Illness perception and quality of life in patients with contact dermatitis. Contact Dermat., 67, 193-199 (2012)

7) Appell RA, Chancellor MB, Zobrist RH, Thomas H, Sanders SW. Pharmacokinetics, metabolism, and saliva output during transdermal and extended-release oral oxybutynin administration in healthy subjects. Mayo Clin. Proc., 78, 696-702 (2003).

8) Chapple C, Khullar V, Gabriel Z, Dooley JA. The effects of antimuscarinic treatments in overactive bladder: a systematic review and meta-analysis. Eur. Urol., 48, 5-26 (2005).

9) Di Nardo A, Sugino K, Wertz P, Ademola J, Maibach HI. Sodium lauryl sulfate (SLS) induced irritant contact dermatitis: a correlation study between ceramides and in vivo parameters of irritation. Contact Dermat., 35, 86-91 (1996).

10) Yokota M, Maibach HI. Moisturizer effect on irritant dermatitis: an overview. Contact Dermat., 55, 65-72 (2006).

11) Held E, Agner T. Comparison between 2 test models in evaluating 
the effect of a moisturizer on irritated human skin. Contact Dermatit., 40, 261-268 (1999).

12) Ramsing D, Agner T. Preventive and therapeutic effects of a moisturizer: an experimental stydy of human skin. Acta Derm. Venereol., 77, 335-337 (1997).

13) Ooi K, Ando M, Hiramoto $K$. The research for the prevention of dermopathy to transdermal delivery systems of oxybutynin patch. Jpn. Pharmacol. Ther., 43, 1419-1429 (2015).

14) Björklund S, Engblom J, Thuresson K, Sparr E. Glycerol and urea can be used to increase skin permeability in reduced hydration conditions. Eur. J. Pharm. Sci., 50, 638-645 (2013).

15) Lee SG, Kim SR, Cho HI, Kang MH, Yeom DW, Lee SH, Lee S, Choi YW. Hydrogel-based ultra-moisturizing cream formulation for skin hydration and enhanced dermal drug delivery. Biol. Pharm. Bull., 37, 1674-1682 (2014).

16) Ooi K, Mitani N, Numajir S, Morimoto Y. Appropriate method for applying fentanyl patches. Jpn. Pharmacol. Ther., 36, 589-592 (2008).

17) Roskos KV, Maibach HI, Guy RH. The effect of aging on percutaneous absorption in man. J. Pharmacokinet. Biopharm., 17, 617-630 (1989).

18) Kornick CA, Santiago-Palma J, Moryl N, Payne R, Obbens EA. Benefit-risk assessment of transdermal fentanyl for the treatment of chronic pain. Drug Saf., 26, 951-973 (2003).

19) Small G, Dubois B. A review of compliance to treatment in Alzheimer's disease: potential benefits of a transdermal patch. Curr. Med. Res. Opin., 23, 2705-2713 (2007).

20) Prausnitz MR, Mitragotri S, Langer R. Current status and future potential of transdermal drug delivery. Nat. Rev. Drug Discov., 3, 115-124 (2004).

21) Miyamoto $T$, Nojima $H$, Shinkado $T$, Nakahashi $T$, Kuraishi Y. Itchassociated response induced by experimental dry skin in mice. Jpn. J. Pharmacol., 88, 285-292 (2002).

22) Tominaga M, Ozawa S, Tengara S, Ogawa $H$, Takamori K. Intraepidermal nerve fibers increase in dry skin of acetone-treated mice. $J$. Dermatol. Sci., 48, 103-111 (2007).

23) Nojima H, Carstens MI, Carstens E. C-fos expression in superficial dorsal horn of cervical spinal cord associated with spontaneous scratching in rats with dry skin. Neurosci. Lett., 347, 62-64 (2003).

24) Rissmann R, Oudshoorn MH, Hennink WE, Ponec M, Bouwstra JA. Skin barrier disruption by acetone: observations in a hairless mouse skin model. Arch. Dermatol. Res., 301, 609-613 (2009).

25) Tsai JC, Sheu HM, Hung PL, Cheng CL. Effect of barrier disruption by acetone treatment on the permeability of compounds with various lipophilicities: implications for the permeability of compromised skin. J. Pharm. Sci., 90, 1242-1254 (2001).

26) Lindh JD, Bradley M. Clinical effectiveness of moisturizers in atopic dermatitis and related disorders: a systematic review. Am.J.
Clin. Dermatol., 16, 341-359 (2015).

27) Ali SM, Yosipovitch G. Skin pH: from basic science to basic skin care. Acta Derm. Venereol., 93, 261-267 (2013).

28) Uchida K, Yamaguchi H. Studies on the affinity of terbinafine with keratine. Jpn. J. Med. Mycol, 34, 207-212 (1993).

29) Norlén L. Stratum corneum keratin structure, function and formation-a comprehensive review. Int. J. Cosmet. Sci., 28, 397-425 (2006).

30) Wurster DE, Kramer SF. Investigation of some factors influencing percutaneous absorption. J. Pharm. Sci., 50, 288-293 (1961).

31) Nakashima M, Zhao MF, Ohya H, Sakurai M, Sasaki H, Matsuyama K, Ichikawa M. Evaluation of in-vivo transdermal absorption of cyclosporin with absorption enhancer using intradermal microdialysis in rats. J. Pharm. Pharmacol., 48, 1143-1146 (1996).

32) Nakamura M, Uemura K, Nemoto O, Miyachi Y. Evaluation of an optimal method for topical application of moisturizer. Skin Research, 5, 311-316 (2006).

33) Ohtani M, Ohtani M, Nozawa A, Matsumoto M, Yamaura Y, Komoda M, Etoh T. A study of the influence of the volume and frequency of application on the efficacy of moisturizers. Jpn. J. Dermatol., 122, 39-43 (2012).

34) Ando T, Shiraishi H, Masai T, Nakamura $Y$, Kamata T, Umemoto J. The effect of creamc containing mucopolysaccharide polysulfate on the skin surface water content-comparison with various skin creams. JCSS, 8, 246-250 (1984).

35) Namba K. Effect of mucopolysaccharide polysulfate (MPS-PS) on the experimental dry skin model. J. Kurume Med. Assoc., 51, 407-415 (1988).

36) Milani M, Sparavigna A. The 24-h skin hydration and barrier function effects of a hyaluronic $1 \%$, glycerin $5 \%$, and Centella asiatica stem cells extract moisturizing fluid: an intra-subject, randomized, assessor-blinded study. Clin. Cosmet. Investig. Dermatol., 10, 311315 (2017).

37) Higuch T. Rate of release of medicaments from ointment bases containing drugs in suspension. J. Pharm. Sci., 50, 874-875 (1961).

38) Khire A, Vavia P. Bioavailability, bioequivalence, and in vitro-in vivo correlation of oxybutynin transdermal patch in rabbits. Drug Deliv. Transl. Res., 4, 105-115 (2014).

39) Paul DR. Elaborations on the Higuchi model for drug delivery. Int. J. Pharm., 418, 13-17 (2011).

40) Higuchi WI, Higuchi T. Theoretical analysis of diffusional movement through heterogeneous barriers. J. Pharm. Sci., 49, 598-606 (1960).

41) Takano K, Nakano M, Taniyama K, Minami K. A study to elucidate the effect of application conditions of a percutaneously absorbed type beta-1 blocker in healthy adults. Med. Cons. New-Remed., 53, 895-902 (2016). 